\title{
SEMIÓTICA DE LA NARRACIÓN JUDICIAL: UN CASO DE VIOLENCIA DE GÉNERO
}

\section{A SEMIOTIC APPROACH TO FORENSIC NARRATIVE. A GENDER VIOLENCE CASE}

\author{
Alicia VALVERDE VELASCO \\ Universidad de Almería \\ avelasco@ual.es \\ Susana RIDAO RODRIGO \\ Universidad de Murcia \\ sridao@um.es
}

Resumen: En el marco de la investigación interdisciplinar, la combinación de los principios teóricos de la narratología y la lingüística forense ofrece la posibilidad de llegar a un conocimiento más preciso en el análisis del discurso de un juicio de violencia de género.

Abstract: In the framework of interdisciplinary research, combining theoretical principles of Narratology and Forensic Linguistics offers the possibility to reach a more precise discourse analysis of a trial of domestic violence. 
Palabras clave: Lingüística forense. Narración oral. Análisis crítico del discurso. Narratología. Semiótica.

Key Words: Forensic Linguistics. Storytelling. Critical Discourse Analysis. Narratology. Semiotics.

\section{UNA APROXIMACIÓN INTERDISCIPLINAR AL DISCURSO JUDICIAL SOBRE VIOLENCIA DE GÉNERO}

La violencia de género ha puesto más que nunca de relieve la profunda conexión existente entre el lenguaje y la realidad social, hasta el punto de llegar a modelar determinados aspectos discursivos que expresan esa compleja relación entre individuos. La imbricación de las estructuras sociales y del lenguaje es observable en la creación de un discurso propio, del que un ejemplo pueden ser las narraciones de los juicios orales por maltrato, como es el caso del corpus que tomamos como base de estudio para este artículo.

Nuestro objetivo es describir los componentes discursivos y narrativos que caracterizan el discurso judicial, atendiendo tanto a la enunciación como a la configuración del relato de los hechos. En ese sentido, el enfoque semiótico, como marco de reflexión y análisis, nos permite abordar el discurso judicial desde una perspectiva inter y transdisciplinar (narratología y lingüística forense), a la vez que desde los diversos planos (sintáctico, semántico y pragmático) de su funcionamiento como texto vinculado a un fenómeno sociocultural, además, de urgente erradicación.

\subsection{El corpus}

Como muestra para nuestro análisis de la narración oral en los contextos judiciales hemos seleccionado - y adjuntamos al final del artículo- un fragmento de diecisiete minutos de una vista oral que tuvo lugar en el año 2000 en los Juzgados de lo Penal de Almería capital. En este caso, sometemos a estudio la versión dada por acusador y acusadora, con el fin de contrastar las diferencias existentes en ambos relatos. Como sabemos, en un juicio se enfrentan dos partes con intereses totalmente contrarios; de un lado, el bloque acusador, quien en todo momento pretende demostrar la culpabilidad del acusado; del otro, el bloque defensor, que pone de manifiesto la inocen- 
cia de aquel. En medio de todo este complejo entramado comunicativo hallamos al juez, que, paradójicamente, a pesar de ser quien menos intervenciones asume, es el que adquiere el rol más importante, pues se encarga de dirimir la sentencia. En consecuencia, los interrogatorios que tienen lugar entre los actores legales (fiscales y abogados, ya sean acusadores o defensores) y los actores sociales (acusados, acusadores y testigos) tienen como objetivo defender los intereses propios (en caso de participantes sociales) o de sus clientes o representados (para los participantes legales).

\section{LA LINGÜÍSTICA FORENSE Y EL ANÁLISIS DEL DISCURSO JUDICIAL}

En realidad, las investigaciones en los contextos legales tomando como objeto de estudio el lenguaje tienen una amplia tradición, porque desde antaño mostraron interés por este tema autores de la talla de Aristóteles o Cicerón. No obstante, hemos de señalar que la etapa de decadencia vivida durante la Edad Media por la retórica influyó directamente en el desinterés tomado por la palabra hablada en los contextos judiciales. Será en el siglo XIX cuando veamos aparecer distintos trabajos en el panorama español sobre la instrucción en el arte de la retórica destinados a la formación de abogados (Sáinz de Andino 1828, Pérez de Anaya 1849, Badioli 1864 y Zamora 1892).

Centrados ya en el siglo XX y lo que llevamos del XXI, rápidamente constatamos que en el ámbito anglosajón hay una fecunda trayectoria investigadora en el campo forense, tomando como base corpus orales, la cual se inicia con diversos estudios fechados en los años sesenta, si bien esta tendencia se desarrolla durante la década de los ochenta, y en los noventa y lo que llevamos de nuevo siglo asistimos a una auténtica consolidación de esta rama de estudio. Prueba de ello es la creación de la International Association of Forensic Linguistics (http://www.iafl.org), promotora del prestigioso International Journal of Speech, Language and the Law, publicación nacida en 1994 con el nombre Forensic Linguistics, si bien en 2003 se decidió cambiar el título del mismo para adaptarlo en mayor medida a sus objetivos y contenidos. Estos investigadores - la mayoría de origen anglosajón - se han centrado principalmente en analizar el contexto judicial aplicado a la teoría de la comunicación, a la lingüística discursivo-textual, a la sociolingüística, a la psicolingüística y a la psicología social, a la traducción, a la pragmática, a la retórica, a la etnometodología, a la semiótica y a la etnografía, entre otras disciplinas. 
Si analizamos el panorama hispanohablante, nos daremos cuenta de la existencia de grandes diferencias, especialmente en la temática de las investigaciones y en el perfil cuantitativo de estos estudios. En español hay una arraigada tradición de trabajar con corpus escritos, situación que se extiende a las publicaciones sobre lenguaje legal. Por ello, los estudios realizados en español suelen encuadrarse en dos grupos: en primer lugar, hallamos una sólida línea de trabajos sobre lenguaje legal efectuados con corpus fechados con anterioridad al siglo XIX, lo que implica que la historia de la lengua se ha preocupado por abordar esta situación; en segundo lugar, observamos estudios descriptivos sobre el lenguaje jurídico e incluso administrativo. En nuestra opinión, son principalmente dos los motivos que justifican esta situación: (1) la enraizada práctica en los investigadores lingüísticos hispánicos a decantarse por analizar corpus escritos; y (2) la reticencia de muchos profesionales en los contextos legales a permitir la grabación de vistas orales con fines investigadores, prevaleciendo la total privacidad de las personas implicadas.

Aun así, hallamos algunos trabajos en español que se han basado en grabaciones orales, reconociendo que numéricamente son muy inferiores a los encontrados en lengua inglesa. Tal es el ejemplo de Quesada (1991, 1993 y 1998), Boretti (1996), Hernández Terrés (1997), Montolío (2000) o Ridao (2004, 2007a, 2007b, 2008b, 2009, 2010a y 2010b). Los dos primeros autores citados se sitúan en Costa Rica y Argentina respectivamente, mientras que el resto ha realizado sus estudios desde España, más en concreto Montolío recoge el corpus en los juzgados catalanes, Hernández Terrés en tribunales murcianos y Ridao se basa en juicios almerienses.

En el artículo que nos ocupa nos encargaremos de analizar la narración oral en un juicio de violencia de género. Precisamente los contextos judiciales constituyen corpus muy interesantes donde podemos observar la narración oral emitida por las partes implicadas en el conflicto, cuya característica más relevante es la ingente diferencia que suele haber entre la versión dada por la parte acusada y la acusadora. Podemos encontrar algunos trabajos publicados sobre esta cuestión donde se pone en evidencia este desajuste a la hora de contar los hechos sucedidos, como es el caso de Bennett (1978), Wodak (1985), Papke (ed.) (1991), Maley (1994), Jackson (1995), Walker (1995), Brooks y Gerwirtz (eds.) (1996) o Cotterill (2003), entre otros. En Ridao (2008a) ofrecemos un amplio y detallado estado de la cuestión en los estudios sobre lenguaje legal, tanto en el ámbito anglosajón como en el hispánico. 


\title{
2.1. Análisis crítico del corpus
}

Con el fin de explicar lo que entendemos por análisis crítico del discurso facilitamos el siguiente fragmento, donde van Dijk establece los principios sobre los que basa este relativamente reciente método de análisis y sugiere sus múltiples aplicaciones:

\begin{abstract}
Although there are many directions in the study and critique of social inequality, the way we approach these questions and dimensions is by focusing on the role of discourse in the (re)production and challenge of dominance. Dominance is defined here as the exercise of social power by elites, institutions or groups, that results in social inequality, including political, cultural, class, ethnic, racial and gender inequality. This reproduction process may involve such different «modes» of discourse-power relations as the more or less direct or even support, enactment, representation, legitimation, denial, mitigation or concealment of dominance, among others. More specifically, critical discourse analysis want to know what structures, strategies or other properties of text, talk, verbal interaction or communicative events play a role in these modes of reproduction (1993: 249-250).
\end{abstract}

Por tanto, debemos asumir que a través del discurso se transmite ideología, y, en consecuencia, que podemos utilizar — es más, consideramos que es una práctica muy extendida - un discurso partidista e interesado, como corroboramos en el corpus que estamos sometiendo a estudio. Si hacemos un análisis de las variables semióticas utilizadas por los actores de este juicio, nos percataremos de que nos permiten describir los posicionamientos de los distintos participantes. A esta altura conviene recordar la información que aportábamos en la introducción, donde aludíamos a la división de los actores que participan en un juicio en función de sus intereses y del poder que ejerce en este contexto: (1) el juez es quien debe dictar la sentencia; (2) el bloque acusado tiene como objetivo la defensa - si bien es cierto que en España partimos de la presunción de inocencia—; (3) el bloque acusador ha de demostrar que el acusado es culpable del delito que se le imputa.

La combinación de diversas variables semióticas, en particular DECIR y NO DECIR cruzadas con QUERER / NO QUERER / PODER / NO PODER / SABER / NO SABER (Jiménez Cano, 1999) nos ofrece una variedad de categorías discursivas que nos permiten describir las intenciones comunicativas de los hablantes. En esta investigación, al estar relacionada con una vista oral, preponderamos la variable DECIR en detrimento de HACER, pues nuestro objetivo se centra en indagar en el discurso (DECIR) emitido por los participantes, principalmente por el acusado y la acusadora, si bien a los hechos (HACER) en esta ocasión le 
otorgamos una relevancia de segundo orden. He aquí la tabla donde sistematizamos las combinaciones de estas variables semióticas:

\begin{tabular}{|c|c|}
\hline DECIR/QUERER—COmpromiso & NO DECIR/QUERER——Preocupación \\
\hline DECIR/NO QUERER- $—$ Continencia & NO DECIR/NO QUERER——Indiferencia \\
\hline DECIR/PODER-Consolidación & NO DECIR/PODER—Abstinencia \\
\hline DECIR/NO PODER——Reivindicación & NO DECIR/NO PODER_—Impotencia \\
\hline DECIR/SABER—Aseveración & NO DECIR/SABER \\
\hline DECIR/NO SABER—Obcecación & NO DECIR/NO SABER——Prevención \\
\hline
\end{tabular}

Cuadro 1: Ridao (en prensa)

Comenzando este análisis con la figura del juez, en este punto del proceso judicial nos encontramos con un claro NO DECIR ante los hechos que se están juzgando, porque su rol en este contexto así lo indica, aunque en la fase posterior, al hacer pública la sentencia, este actor ya hace gala de un DECIR. Recordemos que la situación del juez puede resultar un tanto contradictoria, en el sentido de que, a pesar de ser el participante con mayor poder (es el encargado de dictar la sentencia), apenas asume intervenciones, sino que se limita a presentar el juicio, distribuir los turnos de habla y, solo en caso de que considere que alguna cuestión importante no ha sido aclarada, formular preguntas a los actores interrogados. No obstante, con la elaboración de la sentencia constata una posición de DECIR, PODER y SABER — combinación que nos facilita un discurso de consolidación y de aseveración respectivamente-, pues es la única figura autorizada para llevar a cabo este procedimiento y, además, debe conocer los pormenores de los hechos que han desembocado en esta vista oral.

La situación de las partes, tanto acusadora como acusada, desde la perspectiva de la semiótica, es bastante similar, porque ambos bloques juegan desde el mismo nivel etnometodológico (PODER) y con las mismas intenciones: convencer al juez de la veracidad de su posición. Estos actores muestran un DECIR y un QUERER; esto es, un discurso de compromiso, ya que presentan la necesidad de aclarar los hechos sucedidos. Resulta obvio pensar que en determinadas ocasiones estos participantes, con el fin de velar por sus intereses, opten por ocultar determinados datos (discurso de inhibición al unir un NO DECIR y SABER). Por ello, recurren al DECIR o al NO DECIR, pues dan a conocer 
la información que les interesa, al tiempo que ocultan —o tratan de hacerlo- la que creen que no les resultará favorable difundir. Por ejemplo, en este fragmento observamos que el acusado en un primer momento manifiesta no saber lo que es la violencia psíquica, e inmediatamente lo niega dos veces, en la primera ocasión con mayor firmeza - a pesar del alargamiento que puede transmitir algo de duda - y en la segunda ocasión alude, de nuevo, a la variable NO SABER (discurso de obcecación):

63- LETRADO: ¿ ¿usted ejercía violencia psíquica sobre su mujer? III (2,5”) 64- ACUSADO: es que no sé lo que es violencia psíquica yo nooo que yo sepa no $\S$

En este otro fragmento es la acusadora quien recurre al NO SABER, dando la impresión de que, en cierto modo, está defendiendo los intereses del acusado - situación que se repite en bastantes ocasiones durante su interrogatorio- - puesto que ella no está mostrando una posición segura ante los episodios de malos tratos; es más, ha sacado a relucir una causa atenuante, que incluso puede llegar a ser eximente, como es la ingesta de alcohol:

91- FISCAL: le insultaba ¿con qué tipo de insultos? //

92- TESTIGO: no [sé

93- FISCAL: in]sultos más bien fuertes es decir /

94- TESTIGO: pues decirme palabras que yo no sé // yo no sé a qué venían a cuento / siempre como venía bebi(d)o §

\section{LA NARRATOLOGÍA Y EL ANÁLISIS DEL RELATO}

El interés epistemológico por el relato, que podemos remontar hasta Aristóteles, se ha materializado en un campo de estudio fructífero a través de los análisis semionarrativos del último siglo. Entre el conjunto de trabajos vamos a destacar las aportaciones estructuralistas, especialmente pertinentes por su descripción de los esquemas narrativos que rigen la construcción de un relato, como las de Barthes, Bremond o Todorov, expuestas a mediados de los sesenta en el volumen colectivo Análisis estructural del relato y los estudios posteriores de índole más sociológica y semiótica, como los de Kristeva o Lotman, entre otros, que vincularon las estructuras textuales, superficiales o discursivas con estructuras profundas o extratextuales, en las que están contenidas las creencias y los valores socioculturales. 
La relevancia de sus propuestas para este caso se justifica por el amplio corpus teórico legado por estos autores para la reflexión sobre los elementos constituyentes de los textos narrativos y los sistemas de relaciones que los regulan. Aun pudiendo objetar ciertas limitaciones en los modelos de análisis, en lo que respecta, sobre todo, a las teorías estructuralistas - que van a ser las más aplicadas en nuestro análisis-, lo cierto es que hasta el momento representan el principal instrumental técnico de los estudios narratológicos. En ese sentido, sus propuestas son también las que mejor resultado pueden arrojar para sintetizar los componentes y funcionamiento básicos de las estructuras narrativas del discurso judicial, que tienen en común con el relato ficcional la construcción a través del lenguaje, y a su vez del modo y la voz, de un discurso susceptible, por su materialización textual, de ser analizado con parámetros comunes.

\subsection{Descripción de las instancias narrativas del relato judicial}

Nuestra concepción de relato parte de la definición que formula Genette del mismo: «la representación de un acontecimiento o de una serie de acontecimientos, reales o ficticios, por medio del lenguaje, y más particularmente del lenguaje escrito» (1974: 193), matizando - acorde con este autor-, que no se puede asumir en esta definición que un relato fluye espontáneamente en la simple combinación de unas acciones; hay que aceptar su carácter de tecné, de construcción, e incluso de intencionalidad y motivación en su mayor o menor elaboración textual.

Asimismo, y como premisa, consideramos que en la disposición de los hechos a través de un discurso verbal se trabaja, como ya expuso Aristóteles a propósito de los textos poéticos y retóricos (argumentativos), con las nociones de verosimilitud y coherencia textual, por lo que desde nuestra perspectiva de análisis no buscamos establecer la presencia o no de verdad en el relato de los hechos, sino el modo en que se realiza la compositio de los mismos.

En el caso que nos ocupa, podemos afirmar que el texto narrativo pertenece a lo que Albaladejo (1986) considera que es un modelo de mundo de lo verdadero, frente al de lo ficcional verosímil y lo ficcional no verosímil; es decir, se elabora con instrucciones de la realidad efectiva. Esto nos lleva a establecer que en el relato judicial los emisores (personas que intervienen en ella) y los receptores (del corpus dado, en nuestro caso) no mantienen un pacto narrativo en el que se acepta voluntariamente entrar en el juego de la 
ficción y suspender la no-creencia, sino que se acepta creer en los hechos expuestos, mientras no existan pruebas fehacientes que demuestren lo contrario. No obstante, tanto en un texto narrativo ficcional como en uno basado en un modelo de mundo verdadero, está presente la condición de verosimilitud, la capacidad de hacer creíble el relato a partir de su disposición textual.

Expuestas estas cuestiones previas, hemos de establecer para el análisis narratológico la distinción básica de las instancias presentes en un relato propuesta por Todorov (1974: 157-158) — que provenía de la retórica inventio/dispositio y de la formalista fábula/sujeto - entre historia, los acontecimientos que son el punto de partida del relato en cuestión, y el discurso ${ }^{1}$, entendido éste como la disposición textual de tales hechos a través, en este caso, del lenguaje verbal. Por tanto, la historia se constituye como una sucesión de situaciones de violencia doméstica, que llega al receptor a través del discurso - el texto de la transcripción-, en el que vamos a distinguir, operativamente, dos secuencias (Bremond, 1974: 88-89):

a) La Secuencia del Juicio (SJ), en la que varias personas hablan sobre un suceso de violencia de género. A través de la forma del diálogo - entendido en cuanto a su estructura, ya que se trata de un interrogatorio y no de una conversación-, la información se presenta al receptor de forma relativamente objetiva, porque no interviene la voz narrativa y el lector puede extraer sus propias conclusiones sobre la escena que se desarrolla en el ámbito de un juzgado, y donde los actores no dejan duda sobre su función en aquella (acusado, letrado, fiscal, juez y acusadora). La secuencia estaría constituida por las siguientes funciones, o unidades mínimas del esquema de una acción (apertura, desarrollo y cierre):

F1. Se abre la posibilidad de conocer los hechos.

F2. Investigación: se añaden datos con la declaración del acusado y la acusadora.

F3. Se puede llegar a conocer el resultado del proceso (dado que el corpus es un fragmento inconcluso, esta función quedaría pendiente de establecer).

\footnotetext{
${ }^{1}$ Hay autores que distinguen hasta tres niveles en el texto narrativo. Por citar algunas propuestas: historia (el significado o material temático), relato (el significante o texto) y narración (proceso por el que al material se le da forma en el marco textual) (Genette, 1970: 193-208); y discurso (lo que se ofrece a la lectura) e historia, diferenciando en ésta, a nivel metodológico, entre el argumento (la presentación de la trama) y la historia (motivos en orden cronológico) (Bobes Naves, 1993: 140-141).
} 
Esta secuencia aparece conectada a otra por el procedimiento del encla$v e$, de modo que para que la SJ pueda desarrollarse y alcanzar su desenlace necesita incluir, o más bien reconstruir, una segunda, que vamos a denominar Secuencia de las Agresiones (SA), cuya estructura exponemos a continuación.

b) La Secuencia de las Agresiones (SA), anterior al momento de la conversación y transmitida a través de una focalización interna. Está constituida por las siguientes funciones, en las que se concentra la acción narrativa del fragmento:

F1. Inicio de la situación de maltrato (el marido, ebrio, amenaza a la mujer con usar una pistola contra ella).

F2. Reiteración de esa situación (el marido, ebrio, intimida a la mujer con un machete en el domicilio conyugal por la mañana, después de una noche de ausencia).

F3. Cierre de la situación de maltrato: la mujer denuncia al marido y las hijas van al psicólogo.

En esta secuencia, descrita principalmente a través de las voces narrativas del fiscal y la acusadora, observamos una mayor presencia de recursos relacionados con el tiempo narrativo, en concreto dos, que se utilizan como mecanismo para reducir la duración del tiempo en su disposición textual respecto del tiempo de la historia:

a) El sumario:

85- FISCAL: veinte ]cuatro años aproximadamente / usted concretamente el año pasado / en septiembre / eeeh realizó una comparecencia en la comisaría policial de Almería realizando una serie de manifestaciones / posteriormente usted sobre estos hechos declaró en el en el Juzgado deee de instrucción ¿recuerda usteeed estas dos declaraciones? §

b) Las elipsis:

95- FISCAL: en con en concretooo usted también declara en el Juzgado queee hace ocho años / refiriéndoseee estamos en noviembre del noventa y nueve / eh en noviembre del noventa y nueve usted declaró queee aproximadamente hacía ocho años / su marido la amenazó con un machete [...]

Cabe destacar por su significación discursiva la utilización del relato repetitivo al aparecer varias veces mencionados en el discurso unos aconteci- 
mientos que suceden una sola vez en la historia. Esta técnica resulta muy pertinente para el relato judicial, cuya estructura dialógica se basa precisamente en la reiteración de la narración de los hechos desde todas las perspectivas posibles:

67- LETRADO: entonces usted en ningún momento durante el durante su matrimonio / ni la ha pegado no la ha amenazado $\$$

68- ACUSADO: yo pegarle NUNCA §

132- LETRADO:. ${ }^{o}$ (de mutuo acuerdo). ${ }^{\circ}$ / vamos a ver USTED HA DICHO que su marido la insultaba /

133- TESTIGO: bueno me insultaba pues yo no sé porque a lo mejor llegaba a veces bebi(d)o yyy / uf yo qué sé pues me decía a lo mejor cosas que no / que no me agradaban $\$$

A diferencia de la SJ, en la que el tiempo de la historia y el tiempo del discurso coinciden (escena), la SA se constituye como una analepsis respecto de aquella, en tanto que supone una recreación de un suceso anterior, en el cual, y a través de los dos narradores (el acusado y la acusadora), se refiere la historia eliminando acontecimientos (elipsis) y sintetizando sus elementos esenciales (sumario) $)^{2}$.

Respecto a las personas que intervienen en el relato judicial, vamos a plantear el uso del modelo actancial de Greimas (1973), para tratar de describirlas a partir de una doble dimensión: (1) su caracterización — son actores, con un perfil humano, en este caso real, a diferencia de la ficción narrativa (hemos de matizar, además, que el uso de actor aquí no tiene relación con el que habitualmente se emplea como participante en un hecho dado) y (2) su función - son también actantes, cumplen un papel en relación con las acciones-. Por tanto:

a) Como actantes, las personas que intervienen en la acción de la SJ aparecen con una función perfectamente definida a través de la denominación de los mismos (juez, acusado, fiscal, letrado y acusadora), de la que se desprende una primera caracterización en oposición: defensa/acusación. Dado que tenemos dos secuencias, cabe la posibilidad de establecer dos clasificaciones de los actantes, entre los que se incluyen también ciertos valores que actúan en el desarrollo de los acontecimientos:

\footnotetext{
${ }^{2}$ Según la tipología de Genette, Figuras III (1989).
} 
- SJ: celebración del juicio:

\begin{tabular}{|l|l|}
\hline SUJETO & Juez \\
\hline OBJETO & Esclarecer la verdad \\
\hline DESTINADOR & Justicia \\
\hline DESTINATARIO & Acusadora-víctima \\
\hline AYUDANTE & Fiscal \\
\hline OPONENTE & Acusado \\
\hline
\end{tabular}

- SA: situación de violencia de género (hay que matizar que el papel del sujeto aparece minimizado por las valoraciones de la acusadora):

\begin{tabular}{|l|l|}
\hline SUJETO & Acusado \\
\hline OBJETO & Ejercer control \\
\hline DESTINADOR & Ira, alcohol \\
\hline DESTINATARIO & Acusadora, hijos \\
\hline AYUDANTE & Violencia \\
\hline OPONENTE & Policía \\
\hline
\end{tabular}

b) Para definirlos como actores, tendremos que remitirnos a la descripción explícita de los individuos o a los rasgos connotativos que subyacen en actitudes y comportamientos:

- El acusado y la acusadora han estado casados durante veinticuatro años, pero actualmente están divorciados, aunque tienen una diferente percepción de este hecho.

- El acusado tiene un presunto carácter violento, aunque lo niega.

- La víctima y el acusado mantienen una actitud dubitativa respecto a los hechos de violencia doméstica a los que se alude en el discurso y, por tanto, contribuyen a la imprecisión del perfil psicosocial que pueden tener ambos. 
- La víctima aduce problemas psicológicos.

- Ambos tienen hijos, que han padecido problemas psicológicos por la situación vivida.

Por último, consideramos interesante hacer referencia a la construcción del espacio en este relato. Si bien la secuencia dialógica del juicio carece de descripción espacial y sólo nos aproximamos a él de forma connotativa - a través del rol de los personajes, por ejemplo-, la secuencia descrita por la acusadora sobre la violencia de género nos ofrece una configuración más significativa del lugar en que se desarrollan los acontecimientos: el hogar.

El domicilio conyugal, desde su dimensión como ámbito de actuación (Valles, 1999), donde acontecen los hechos, se presenta como una inversión del topos del hogar, entendido como lugar de refugio, para transformarse en el topos del conflicto, en el espacio que acoge las agresiones: «ha llega(d)o bebi(d)o y entonces me ha da(d)o cualquier empujón a lo mejor al entrar», afirma la acusadora, adquiriendo los verbos «venir» o «llegar» un valor connotativo de detonante de la violencia doméstica en contacto con el espacio familiar.

\section{CONCLUSIONES}

En estos momentos la investigación apuesta firmemente por los proyectos de naturaleza interdisciplinar, precisamente porque en estudios como el que hemos realizado se hace evidente la pertinencia de introducir propuestas teóricas que amplíen las perspectivas de análisis de un fenómeno dado.

Por un lado, la funcionalidad de los principios narratológicos en textos no ficcionales se basa en que sus componentes estructurales son comunes a los del relato de ficción, de manera que pueden ser descritos en términos similares: organización de las secuencias, distribución de papeles actanciales, descripción de los actores, recursos en la utilización del tiempo, configuración del espacio, voz y modos del relato, etc.; es decir, cuando se narra un hecho se busca la coherencia del relato, el narrador determina qué y cómo se cuenta, lo que influye de manera directa en la significación y la recepción del mismo.

Por otro lado, la lingüística forense ha captado la atención de numerosos investigadores en áreas muy diferentes; una de las más fecundas ha sido el análisis discursivo-textual y también, desde el contexto anglo- 
sajón, se ha mostrado predilección por realizar investigaciones sobre narración oral. En estos contextos comunicativos, como son las vistas orales, entran en juego la dimensión semiótica (semántico-pragmática) del DECIR frente al NO DECIR.

A la par, las variables del SABER, PODER y QUERER, junto con sus modalidades negativas, contribuyen a la creación de un discurso en el que los actores cifran sus mensajes en función de sus intereses y su rol, como actantes en el marco de las secuencias en las que intervienen y, al mismo tiempo, como voces que construyen un relato orientado a persuadir al juez sobre la veracidad de sus palabras.

Otros aspectos narratológicos característicos del discurso judicial estarían relacionados con el uso del tiempo y el espacio. Del primero, cabe destacar el relato repetitivo, según el cual se reiteran en varias ocasiones acciones que suceden una sola vez en la historia, pero que resultan de vital importancia para el desenlace del juicio. En cuanto al espacio, hay que señalar que en un juicio de violencia doméstica el hogar, como ámbito de actuación, adquiere un valor significativo a partir de las acciones que se desarrollan en él, convirtiéndolo en un topos como lugar de conflicto frente al tradicional concepto de seguridad y confianza.

\section{REFERENCIAS BIBLIOGRÁFICAS}

ALBALADEJO, T. (1986). Teoría de los mundos posibles y macroestructura narrativa. Alicante: Universidad de Alicante.

AYALA, F. (1970). Reflexiones sobre la estructura narrativa. Madrid: Taurus.

BADIOLI, L. (1864). Declamación sagrada, forense, académica, popular, militar y teatral. Madrid: Imprenta de Manuel Galiano.

BARTHES, R. (1974). «Introducción al análisis estructural de los relatos». En Análisis estructural del relato, VV. AA., 9-43. Buenos Aires: Editorial Tiempo Contemporáneo.

BENNETT, W. (1978). «Storytelling in Criminal Trials: A Model of Social Judgement». Quarterly Journal of Speech 64, 1, 1-22.

BOBES NAVES, M. C. (1993). La novela. Madrid: Síntesis.

- (1992). El diálogo. Madrid: Gredos. 
BORETTI, S. (1996). «Análisis de la negación en el discurso legal». En Actas del X Congreso Internacional de la Asociación de Lingüística y Filología de la América Latina, M. Arjona Iglesias et alii (eds.), 635-638. México: Universidad Autónoma de México.

- (1972). La novela. Barcelona: Ariel.

BREMOND, C. (1974). «La lógica de los posibles narrativos». En Análisis estructural del relato, VV. AA., 87-109. Buenos Aires: Editorial Tiempo Contemporáneo.

BROOKS, P. y GERWIRTZ, P. (eds.), (1996). Law's Stories: Narrative and Rhetoric in the Law. New Haven: Yale University Press.

CHATMAN, S. (1990). Historia y discurso. La estructura narrativa en la novela y en el cine. Madrid: Taurus.

COTTERILL, J. (2003). Language and Power in Court: A Linguistic Analysis of the O. J. Simpson Trial. London: Palgrave Macmillan.

ECO, U. (1981). Lector in fabula. Barcelona: Lumen.

GARRIDO LÓPEZ, A. (1993). El texto narrativo. Madrid: Síntesis.

GENETTE, G. (1974). «Fronteras del relato». En Análisis estructural del relato, VV. AA., 193-208. Buenos Aires: Editorial Tiempo Contemporáneo.

- (1989). Figuras III. Barcelona: Lumen.

GREIMAS, A. J. (1973). «Los actantes, los actores y las figuras». En Semiótica narrativa y textual, C. Chabrol et alii, 183-199. Caracas: Universidad de Venezuela.

HERNÁNDEZ TERRÉS, J. (1997). «Particularidades lingüísticas del acto del juicio oral: La función dialógica del juez». En Panorama de la investigación lingüística a l'Estat Espanyol: Actes del I Congrés de Lingüística General, VV. AA. (eds.), 42-47. Valencia: Universidad de Valencia.

JACKSON, B (1995). Making Sense in Law: Linguistic, Psychological and Semiotics Perspectives. Liverpool: Deborah Charles Publications.

JIMÉNEZ CANO, J. M. (1999). «Claves sociosemióticas para el análisis de textos ecologistas». En Estudios de sociolingüística II. Sincronía y diacronía, P. Díez de Revenga y J. M. Jiménez Cano (eds.), 197-218. Murcia: DM Editor.

LOTMAN, I. (1988). Estructura del texto artístico. Madrid: Itsmo. 
MALEY, Y. (1994): «The Language of the Law». En Language and the Law, J. Gibbons, 3-50. London: Longman.

MONTOLÍO DURÁN, E. (2000). «Les estructures condicionals [si P, Q] i la seva rellevància en les formulacions legislatives, administratives i jurídiques». Revista de Llengua i Dret 34, 67-91.

PAPKE, D. (ed.) (1991). Narrative and Legal Discourse: A Reader in Storytelling and the Law. Liverpool: Deborah Charles Publications.

PÉREZ DE ANAYA, F. (1849). Lecciones y modelos de elocuencia forense. Madrid: D. M. Gabeiras.

QUESADA PACHECO, J. (1991). «Análisis de las pruebas testimoniales en juicios penales». Revista de Ciencias Jurídicas 68, 83-95.

- (1993). «Culpable mientras no pruebe su inocencia: Problemas de nuestro sistema jurídico». Revista de Ciencias Jurídicas 76, 61-80.

- (1998). Análisis del discurso oral en el proceso penal. San José de Costa Rica: Universidad Estatal a Distancia.

RIDAO, S. (2004). «Análisis crítico del discurso en contextos judiciales. Propuestas de investigación». Interlingüística 15, 1159-1168.

- (2007a). «El interrogatorio en los contextos judiciales. Estado de la producción científica». Oralia 10, 303-314.

- (2007b). «La figura del intérprete traductor en los juicios con testigos extranjeros. Una aproximación pragmalingüística». En Discurso y oralidad. Homenaje al profesor José Jesús de Bustos Tovar, L. Cortés Rodríguez, A. Bañón Hernández, M. Espejo Muriel y J. Muñío Valverde (coords.), 861-871. Madrid: Arco / Libros.

- (2008a). Análisis pragmalingüístico de resoluciones de conflictos: Las mediaciones laborales. Propuestas de investigación. Almería: Universidad de Almería.

- (2008b). «El interrogatorio en los contextos judiciales. Una aproximación pragmalingüística». En 25 años de lingüística en España: Hitos y retos, R. Monroy y A. Sánchez (eds.), 805-809. Murcia: Universidad de Murcia.

- (2009). «El interrogatorio en los contextos judiciales. Análisis del tipo y la frecuencia de las preguntas utilizadas en los Juzgados de Almería capital». Interlingüística 18, 940-950. 
- (2010a). El género judicial. Materiales para su estudio lingüístico. Anejo de la revista Tejuelo. Didáctica de la Lengua y la Literatura. Extremadura: Junta de Extremadura.

- (2010b). «The Process of Interruption in Spanish Judicial Context. A Pragmalinguistic Aproach». Tejuelo. Didáctica de la Lengua y la Literatura VII, 8-43.

- (en prensa). «Enfermedades raras y discurso. Análisis de las noticias publicadas en el diario El País». En Comunicación y salud. Las enfermedades raras, VV. AA. Sevilla: Arcibel.

SÁINZ DE ANDINO, P. (1828). Elementos de elocuencia forense. Madrid: Imprenta de la Sociedad de Operarios del Mismo Arte.

TALENS, J. et alii (1995). Elementos para una semiótica del texto artístico (Poesía, narrativa, teatro, cine). Madrid: Cátedra.

TODOROV, T. (1974): «Las categorías del relato literario». En Análisis estructural del relato, VV. AA., 155-193. Buenos Aires: Editorial Tiempo Contemporáneo.

VALLES CALATRAVA, J. R. (1999). El espacio narrativo. Almería: Universidad de Almería.

VALLES CALATRAVA, J. R. y ÁLAMO FELICES, F. (2000). Fundamentos de semiótica narrativa. Almería: Universidad de Almería.

VALVERDE VELASCO, A. (2001). «Ayala y el cuento literario. Estructura narrativa de Los usurpadores». En Francisco Ayala, escritor universal, A. Sánchez Trigueros y M. Vázquez Medel (eds.), 223-232. Sevilla: Alfar

VAN DIJK, T. A. (1993). «Principles of Critical Discourse Analysis». Discourse \& Society 4 (2), 249-283.

VILLANUEVA, D. (1977). Estructura y tiempo reducido en la novela. Valencia: Bello.

WALKER, A. (1995). «Story Models and Storytelling in the Courts». En Legal Communication: Skills and Practice, L. Keele. Brown: Dubuque.

WODAK, R. (1985). «The Interaction between Judge and Defendant». En Handbook of Discourse Analysis. Vol. IV, T. van Dijk, 181-191. London: Academic Press London.

ZAMORA, L. (1892). Programas para la enseñanza de las asignaturas de procedimientos judiciales y de práctica forense y redacción de instrumentos públicos. Santiago: Imprenta de José M. Paredes. 


\section{ANEXO: TRANSCRIPCIÓN}

1- JUEZ: $\{$ nombre y primer apellido $/$ le acusan de un delito de malos tratos ¿se considera culpable? $\S$

2- ACUSADO:. ${ }^{\circ}\left(\right.$ no).$^{\circ} \S$

3- JUEZ: conteste a las preguntas del señor fiscal $§$

4- FISCAL: con la ve[nia

5- LETRADO:.. $\left.\left.{ }^{\circ}(())\right) .^{\circ}\right]$

6- JUEZ: sí / un segundo §

7- LETRADO:. ${ }^{\circ}$ (con la venia señoría me va usted a perdonar como la acusación particular $(())) .^{\circ} \S$

8- JUEZ: el acto previo no está para esas cosas señor letrado / continúe señor fiscal $\S$

9- FISCAL: con la venia eeeh vamos a ver / usted en principio / en concreto estaba / o está casado con $\{$ nombre y apellidos $\}$ ¿no?

10- ACUSADO: (afirma con la cabeza)

11- FISCAL: ¿estaba o está sigue casado aún? §

12- ACUSADO: estaba $\S$

13- FISCAL: estaba / ahora actualmenteee ¿en qué situación se encuentra? / ¿separado divorciado? §

14- ACUSADO: yo pa(ra) mí que firmééé se la separación $\S$

15- FISCAL: separado / y usted ya no vive con ella ¿no? §

16- ACUSADO:. ${ }^{\circ}\left(\right.$ no) ${ }^{\circ} / /$

17- FISCAL: (aclara la garganta) ¿cuánto tiempo ha vivido usted aproximadamente con ella? / ¿unos veinticuatro años aproximadamente? §

18- ACUSADO: pues en el setenta y cincooo / es decir veinticuatro o veinticuatro años /

19- FISCAL:. ${ }^{\circ}$ (bueno). ${ }^{\circ}$ durante esos veinticuatro añooos / se le acusa a usted en concreto de queee / reiteradamente ha sometido usted a su esposa a malos tratos tratos vejatorios tanto de palabra / insultándola / amenazándola etcétera / como incluso de obra / agrediéndola / agrediéndola también frecuentemente / incluso cooon cuchillos incluso con armas y con // y con 
otros con otros objetos / así mismo pues tambiééén se le acusa de que también se le acusa de que también durante este periodo / concretamente aaa a sus hijas dos hijas que tie tiene usted que convivían supongo con usted / de veintiuno y veintitrés años de edad probablemente / eeeh también habían recibi(d)o de usted malos tratos / ha le había pegado usted y incluso ha intentado usted ((sobrepasar)) pero no hay (( )) / en definitiva se le acusa a usted de realizar un trato vejatorio tanto a sus hijas como a su mujer / de palabra y de obra / duranteee todo el tiempo que usted estuvo casado ooo o que estuvo conviviendo con ellas / ((es ese)) el domicilio conyugal. ${ }^{\circ}$ (¿son ciertos estos hechos o no son ciertos?). ${ }^{\circ} / / /\left(1,5^{\prime \prime}\right)$

20- ACUSADO: ah no he oído bien $\S$

21- FISCAL: que si son ciertos esos hechos [que he dicho

22- ACUSADO: que va]

23- FISCAL: $=$ ¿en absoluto? ¿nunca ha tenido usted ningún problema con ella? /

24- ACUSADO: nunca $\S$

25- FISCAL: ¿nunca? ¿nuncaaa han tenidooo en concreto recuerda usted si alguna vez ha tenido ella que / que acudir aaa a al cuartel de la guardia civil o a la policía a denunciarlo? ¿nunca ha asistido a este tipo de procedimiento? /

26- ACUSADO: que yo sepa no $\S$

27- FISCAL: ¿nunca no han tenido alguna pelea? / supongo que sí ¿no? / durante ese periodo de tiempo / veinticuatro años supongo que alguna pelea que otra habrán tenido ¿o no? pregunto /

28- ACUSADO: peleas nooo / nunca §

29- FISCAL: ¿usted nunca la ha amenazado a ella? §

30- ACUSADO: no (chasquido) §

31- FISCAL: ¿jamás jamás ha amenazado usted ni la ha insultadooo? §

32- ACUSADO:. ${ }^{\circ}\left(\right.$ no).$^{\circ} \S$

33- FISCAL: que recuerde / nunca le ha pegado tampoco $§$

34- ACUSADO: que yo recuerde no $\S$

35- FISCAL: ¿y la relación con sus hijas es buena? § 
36- ACUSADO: de [siem

37- FISCAL: (( ))]

38- ACUSADO: $=$ de siempre han sido buenas $\S$

39- FISCAL: usteeed ¿bebía frecuentemente o alguna vez llegaba a su casa / digamos bebido? §

40- ACUSADO: alguna vez he he he bebido sí §

41- FISCAL: ¿y ha en una de esas ocasiones que usted dice / ha bebidooo y como consecuencia ha debido llegar a su casa / ummm efectivamente / con alguna copa de más como se suele decir / nunca se ha producido ningún problema / en por lo menos en algunas de estas ocasiones a las cuales usted ha aludido? $\S$

42- ACUSADO: que yo recuerde no $\S$

43- FISCAL: entonces a qué [cree usted

44- ACUSADO: regañarme sí me han] regaña(d)o perooo problemas no he teni(d)o $§$

45- FISCAL: ¿a qué cree usted entonces que se debe esta denuncia que su (( )) interpuso? §

46- ACUSADO: pues yo no me lo explico $\S$

47- FISCAL: no tiene usted. $\left.{ }^{\circ}((()))\right)^{\circ} /$ muy bien / pues ninguna pregunta más $\S$

48- JUEZ: señor letrado §

49- LETRADO: venia señoría vamos a ver eeeh /// (3") durante // ¿el matrimonio duró veinticuatro años aproximadamente? / ¿usted estuvo casado veinti[cuatro

50- ACUSADO: aproximadamente sí

51- LETRADO: años aproxi]madamente / vamos a ver ¿usted en algún momento eeeh // ha haaa haaa realizado eh violencia física sobre su mujer? §

52- ACUSADO:. ${ }^{\circ}\left(\right.$ no).$^{\circ} \S$

53- LETRADO: en ningún / NUNCA §

54- ACUSADO: nunca $\S$

55- LETRADO: ¿y sobre sus hijas? § 
56- ACUSADO: no tampoco $§$

57- LETRADO: ¿y sobre su hijo? §

58- ACUSADO: tampoco $\S$

59- LETRADO: tampoco / eeeh ¿durante el matrimonio u usted / eeeh /// (2") amenazaba a su mujer? /// (1,5")

60- ACUSADO: (niega con la cabeza) que yo sepa no $\S$

61- LETRADO: no //

62- ACUSADO:.. $\left.{ }^{\circ}(())\right) .^{\circ} / /$

63- LETRADO: ¿usted ejercía violencia psíquica sobre su mujer? /// (2,5”)

64- ACUSADO: es que no sé lo que es violencia psíquica yo nooo que yo sepa no $\S$

65- LETRADO: que psi / psíquicamente la maltrataba $\S$

66- ACUSADO:.. ${ }^{\circ}$ (nooo). ${ }^{\circ} / /$

67- LETRADO: entonces usted en ningún momento durante el durante su matrimonio / ni la ha pegado no la ha amenazado §

68- ACUSADO: yo pegarle NUNCA §

69- LETRADO: nunca (se oye una tos) nunca eeeh usted entonces ¿por quééé por qué lo denuncia su mujer si dice que esos hechos son no son ciertos? $\S$

70- ACUSADO: pues no tengo ni idea y a mí me gustaría enterarme / también $\S$

71- LETRADO: ya / ninguna pregunta más §

72- JUEZ: siéntese /// (9") pase señora /// (8") \{nombre y apellidos\} §

73- ACUSADORA:. ${ }^{\circ}\left(\right.$ sí $^{\circ}{ }^{\circ} \S$

74- JUEZ: ¿jura o promete decir la verdad? §

75- ACUSADORA:. ${ }^{\circ}\left(\right.$ sí $^{\circ}{ }^{\circ} \S$

76- JUEZ: conteste a las preguntas del señor fiscal §

77- FISCAL: con la venia vamos a ver $\{$ nombre $\}$ usted um // (2,5") está o estuvo casada concretamente con el acusado con con $\{$ nombre y primer apellido\} ¿no? 
78- ACUSADORA: (asiente con la cabeza)

79- FISCAL: ¿se encuentra usted actualmente separada de él?

80- ACUSADORA: (afirma con la cabeza)

81- FISCAL: separada legalmente

82- ACUSADORA: (afirma con la cabeza). ${ }^{\circ}\left(\right.$ sí) $^{\circ} .^{\circ} \S$

83- FISCAL: muy bien / entonces usted ha vivido aproximadamente ha convivido con él aproximadamente cuánto tiempo §

84- ACUSADORA: veinticuatro [años

85- FISCAL: veinti]cuatro años aproximadamente / usted concretamente el año pasado / en septiembre / eeeh realizó una comparecencia en la comisaría policial de Almería realizando una serie de manifestaciones / posteriormente usted sobre estos hechos declaró en el en el Juzgado deee de instrucción ¿recuerda usteeed estas dos declaraciones? §

86- ACUSADORA:. ${ }^{\circ}\left(\right.$ sí $^{\circ} .^{\circ} \S$

87- FISCAL: ¿mantiene usted ratifica lo que usted declaró en esaaas en am en ambas / tanto en la comisaría como en el Juzgado de instrucción? §

88- ACUSADORA: ¿me puede repetir? §

89- FISCAL: que si ratifica usted lo que declaró que si mantiene usted lo que declaró en su contenido es decir son / es cierto lo que declara usted no esas manifestaciones en concreto entonces es cierto queee que su marido durante estos veinticuatro años / según declara usted / eeeh con frecuencia leee le ha insultado $\S$

90- ACUSADORA:. ${ }^{\circ}$ (sí alguna vez hacía mucho tiempo pero de vez en cuando me insultaba). ${ }^{\circ} \S$

91- FISCAL: le insultaba ¿con qué tipo de insultos? //

92- ACUSADORA: no [sé

93- FISCAL: in]sultos más bien fuertes es decir /

94- ACUSADORA: pues decirme palabras que yo no sé // yo no sé a qué venían a cuento / siempre como venía bebi(d)o §

95- FISCAL: en con en concretooo usted también declara en el Juzgado queee hace ocho años / refiriéndoseee estamos en noviembre del noventa y nueve / eh en noviembre del noventa y nueve usted declaró queee aproxi- 
madamente hacía ocho años / su marido la amenazó con un machete y le y le dijo que incluso iba a ver cómo la cabeza le iba a chorrear sangre una una vez ¿eso es cier[to?

96- ACUSADORA: sí] porque llegó una mañana bebi(d)o y sí decía que me iba a

\section{( ...)}

97- ACUSADORA: tenía un machete perooo / porque había llega(d)o bebi(d)o / eran las siete de la mañana $\S$

98- FISCAL: bueno eso ya oiremos laaa la causa ya la diremos / pero en definitiva ratifica usted que efectivamente eso sucedió ¿no? §

99- ACUSADORA: sí me dijo que sí que me iba aaa dar con un machete $\S$

100- FISCAL: eh también usted dijo que no lo denunció por miedo a su reacción / es ese momento $\S$

101- ACUSADORA:. ${ }^{\circ}$ (sí pues no sé porque). ${ }^{\circ}$

102- FISCAL: también declara usted que también de vez en cuando le dice que tiene una pistola y que con la pistola la va a matar / también alguna vez le ha dicho eso no le digo que le haya saca(d)o la pistola sino que le [DICE

103- ACUSADORA: sí]

104- FISCAL: = que tiene una pistola $\S$

105- ACUSADORA: sí me lo ha dicho siempre pero es porque ha llegado bebido yo no sééé $\S$

106- FISCAL: bueno bueno $\S$

107- ACUSADORA: yo no sé §

108- FISCAL: insisto tambiééén tambiééén dice usted que alguna vez se dirige a su hija diciéndole que se va a quedar SIN MADRE y palabras semejantes ¿no? $\S$

109- ACUSADORA: eso yo no lo sé eso es que la niña se ve queee / pero sí que me lo han dicho las niñas a veces / pero que yo nooo yo no $(()) \S$

110- FISCAL: de hechooo inclusooo salió declara(d)o usted aquí que las niñaaas han tenido que seguir un tratamiento psiquiátrico ¿no? y psicológico tuvieron que seguir un trata[miento 
111- ACUSADORA: sí sí] han esta(d)o en tratamiento /

112- FISCAL: con motivo de qué de estas de estos problemas que existían con el padre $\S$

113- ACUSADORA: yo no sé porque se encontraban mal se encontraban mal y ellas pues iban al psicólogo a a olvidarse de sus cosas $\S$

114- FISCAL: también dice usted que le ha pegado con frecuencia // a usted pero que no ha ido al médico pues para evitaaar problemas con él §

115- ACUSADORA: nooo $\S$

116- FISCAL: es decir alguna que otra vez le ha pegado $\S$

117- ACUSADORA: no es que me haya pega(d)o sino que a lo mejor ha llega(d)o bebi(d)o y entonces me ha da(d)o cualquier empujón a lo mejor al entrar o [algo

118- FISCAL: no mire usted

119- ACUSADORA: si yo esta]ba allí §

120- FISCAL: aquí textualmente dice se lo leo que también en en su declaración en el Juzgado de instrucción que textualmente dice que también le ha pegado con frecuencia / pero que no ha ido al médico por no meterse en follones / en la familia y por la reacción a él §

121- ACUSADORA: a lo mejor algún empujón o algún tortazo / perooo de esto hace ya mucho tiempo / [años

122- FISCAL: incluso dice] incluso dice usted / bueno ya / que hace año y medio insisto estamos en noviembre del noventa y nueve sería en el noventa y siete aproximadamente / dice usted queee que su hija llamó incluso un día a la policía ¿no? / [concretamente

123- ACUSADORA: eso me dijo] pero yo yo no sé / es que ella lo comentó pero yo yo no sé /

124- FISCAL: muy bien usted en principio ummm renunció a cualquier tipo de indemnización ¿no? por estos hechos no reclama usted ningún tipo de indemnización por por estos hechos renuncia usted a acciones correspondientes por este asunto // pues ninguna preguntaaa / muchas gracias $\S$

125- JUEZ:. ${ }^{\circ}$ (señor letrado). ${ }^{\circ} \S$

126- LETRADO: con la venia señoría / vamos a ver /// (1,5") es cierto que usted estuvo casada durante veinticuatro años con el acusado ¿no? $\S$ 
127- ACUSADORA:. ${ }^{\circ}\left(\right.$ sí $^{\circ}{ }^{\circ} \S$

128- LETRADO:.. ${ }^{\circ}$ (es cierto). ${ }^{\circ} / /$ es cierto que con fecha seis de marzo / eeeh se puso / una demanda de separación / para para poner fin a la relación ¿es cierto eso?

129- ACUSADORA: (afirma con la cabeza)

130- LETRADO: eh ¿se acuerda usted cómo fue esa separación / si fueee contenciosa fue de mutuo acuerdo? §

131- ACUSADORA:. ${ }^{\circ}$ (más bien de mutuo acuerdo). ${ }^{\circ} \S$

132- LETRADO:.. ${ }^{\circ}$ de mutuo acuerdo). ${ }^{\circ} /$ vamos a ver USTED HA DICHO que su marido la insultaba /

133- TESTIGO: bueno me insultaba pues yo no sé porque a lo mejor llegaba a veces bebi(d)o yyy / uf yo qué sé pues me decía a lo mejor cosas que no / que no me agradaban $\S$

134- LETRADO:. ${ }^{\circ}$ (vamos a ver). ${ }^{\circ} /$ entonces usted dice que cuando la insultaba / era porque estaba siempre bebido /

135- ACUSADORA: sííi porque de vez en cuando venía bebi(d)o y cuando llegaba / más o menos siempre hacia eso §

136- LETRADO: su marido la ha insultado a usted a usted estando alguna vez él ebri eh sin beber

137- ACUSADORA: (niega con la cabeza)

138- LETRADO: nunca / entonces siempre que que la insultaba era porque estaba bajo los efectos de la bebida alcohólica

139- ACUSADORA: (afirma con la cabeza). ${ }^{o}$ (sí sí). ${ }^{\circ} \S$

140- LETRADO: es cierto ¿no?

141- ACUSADORA: (afirma con la cabeza)

142- LETRADO: ¿eso eh era con frecuencia o era esporádicamente / o eran todos los días? §

143- ACUSADORA: no no esporádicamente de vez en cuando tampoco eraaa / lo que pasa es que a lo largo de tantos años de matrimonio pueees alguna vez que otra $\S$

144- LETRADO: ¿puede usted cuantificar a la sala / ummm cuántas veces se han producido / si tres cuatro seis? § 
145- ACUSADORA: exactamente no lo sé pero pocas / un par de veces §

146- LETRADO: un par de veces duran[te

147- ACUSADORA: sí]

148- LETRADO: =durante los veinticuatro años del matrimonio $\S$

149- ACUSADORA: de vez en cuando a lo mejor / el año pasa(d)ooo y otra vez yo no recuerdo y eso pero tampocooo /

150- LETRADO: entonces no eran habitua[les

151- ACUSADORA:. ${ }^{\circ}\left(\right.$ no).$\left.^{\circ}\right]$

152- LETRADO: $=$ los insultos $\S$

153- ACUSADORA:. ${ }^{\circ}$ (no no no). ${ }^{\circ} \S$

154- LETRADO: han si(d)o dos o tres veces durante los veinticuatro años $\S$

155- ACUSADORA: (afirma con la cabeza). ${ }^{\circ}$ (durante los veinticuatro años). ${ }^{\circ} \S$

156- LETRADO: ¿y la última vez que se produjo // puede usted precisar si haceee eh tres meses antes de poner usted la denun[cia?

157- ACUSADORA:. ${ }^{\circ}$ (no más). ${ }^{\circ}$

158- LETRADO: o cin] =co años [antes

159- ACUSADORA:. ${ }^{\circ}$ (hace ya] =hace ya mucho tiempo ya haceee siete u ocho años desde que se usó mi (( )) ). ${ }^{\circ} \S$

160- LETRADO: es decir que la última vez que le insultó su marido estando borracho fue hará unos siete años $\S$

161- ACUSADORA:. ${ }^{\circ}$ (sí sí). ${ }^{\circ} \S$

162- LETRADO: vamos a ver / ¿usted manifestó /// (1,5”) manifestó en el Juzgado / que hace ocho años / la amenazó con un machete? §

163- ACUSADORA: no porque él llegó bebi(d)o y entonces me $\S$

164- LETRADO: entonces no eran habituales los insultos

(...)

165- LETRADO: usted no vio en ningún momento el machete $\S$

166- ACUSADORA:. ${ }^{\circ}$ (no). ${ }^{\circ} \S$ 
167- LETRADO: no / solamente que se produjo cuando él vino borracho §

168- ACUSADORA: ${ }^{\circ}$ (sí sí). ${ }^{\circ} \S$

169- LETRADO: y se lo dijo $§$

170- ACUSADORA:. ${ }^{\circ}\left(\right.$ sí). $^{\circ} \S$

171- LETRADO: ¿usted le tomó en consideración / o no le dio importancia? §

172- ACUSADORA: en esos momentos sí le di importancia pero después no $\S$

173- LETRADO: [des

174- ACUSADORA: después] yo no le di importancia

(...)

175- LETRADO: estando borracho el acusado después de decírselo se acostó o se (( )) /

176- ACUSADORA: se acostó a dormir $\S$

177- LETRADO: ¿y no pasó nada?

\section{Símbolos de transcripción (grupo Val.Es.Co):}

:_Cambio de hablante.

$\S$ Sucesión inmediata, sin pausa apreciable, entre dos emisiones de distintos hablantes.

[ Lugar donde se inicia un solapamiento o superposición.

] Final del habla simultánea.

=Mantenimiento del turno de un participante en un solapamiento.

/ Pausa corta, inferior al medio segundo.

// Pausa entre medio segundo y un segundo.

/// Pausa de un segundo o más.

(5») Silencio (lapso o intervalo) de 5 segundos; se indica el número de segundos en las pausas de más de un segundo.

EN COCHE Pronunciación marcada o enfática. 
(( )) Fragmento indescifrable.

((siempre)) Transcripción dudosa.

$((\ldots))$ Interrupciones de la grabación o de la transcripción.

(en)tonces Reconstrucción de una unidad léxica que se ha pronunciado incompleta. surro.

.${ }^{\circ}(){ }^{\circ}$ Fragmento pronunciado en un tono de voz más bajo, próximo al su-

(risas) Sonidos significativos e información no verbal

aaa Alargamientos vocálicos.

nnn Alargamientos consonánticos.

¿ ? Interrogaciones. También para los apéndices del tipo «¿no?», «¿eh?»,«¿sabes?».

i! Exclamaciones. Expresiones irónicas.

Letra cursiva Reproducción e imitación de emisiones. Estilo directo, característico de los denominados relatos conversacionales.

\{ \} Información confidencial. Por ejemplo, nombres y apellidos, o nombres de empresas, entre otros.

Recibido el 12 de abril de 2011.

Aceptado el 16 de septiembre de 2011. 